\title{
Análises Interseccionais a Partir da Raça e da Classe: Medo do Crime e Autoritarismo no Brasil
}

\author{
Tadeu Lucas de Lavor Filho ${ }^{1}$ \\ ${ }^{1}$ Universidade Federal do Ceará, CE, Brasil. \\ Damião Soares de Almeida Segundo ${ }^{1}$ \\ ${ }^{1}$ Universidade Federal do Ceará, CE, Brasil. \\ Paulo de Martino Jannuzzi ${ }^{3}$ \\ ${ }^{3}$ Escola Nacional de Ciências Estatística do IBGE, \\ RJ, Brasil.
}

\author{
Vilkiane Natercia Malherme Barbosa ${ }^{1}$ \\ ${ }^{1}$ Universidade Federal do Ceará, CE, Brasil. \\ James Ferreira Moura Junior ${ }^{1,2}$ \\ ${ }^{1}$ Universidade Federal do Ceará, CE, Brasil. \\ ${ }^{2}$ Universidade da Integração Internacional da \\ Lusofonia Afro-brasileira \\ Renato Sérgio de Lima ${ }^{4}$ \\ ${ }^{4}$ Fundação Getulio Vargas, SP, Brasil.
}

Resumo: O presente estudo objetivou apresentar, a partir de uma análise interseccional quantitativa, em que medida os marcadores de raça/classe interferem no medo do crime e no autoritarismo em contexto brasileiro. Participaram 2.087 pessoas de todas as regiões do país, em uma amostra representativa da população brasileira, majoritariamente com idades entre 25 e 34 anos (26,3\%), negros (60,0\%) e pertencentes à classe D/E (27,3\%), tendo respondido à Escala F de Adorno (versão 17 itens) e escalas para mensurar o medo, a vitimização e as chances de ocorrência de crimes. Análises de Variância não indicaram diferenças significativas entre raças para o autoritarismo $(\mathrm{F}=2,600 ; \mathrm{p}=0,017)$, quando não considerado o efeito das classes. Contudo, houve diferença significativa entre classes ( $F=14,265 ; \mathrm{p}<=0,001$ ), principalmente dentre os brancos $(\mathrm{F}=11,08$ e $\mathrm{p}<0,05)$. Já na comparação para negros e brancos em classes específicas, apenas no estrato B1 houve diferença significativa $(F=4,54 ; \mathrm{p}<=0,05)$. Níveis elevados de medo do crime aparecem em todas as intersecções de raça/classe, destacadamente dentre os negros de classe $\mathrm{A}(\mathrm{F}=6,52 ; \mathrm{p}<=0,05)$. A partir da análise discriminante dois perfis de agrupamentos com maior e menor medo do crime foram formados a partir de fatores como gênero, idade, raça, classe, chances de sofrer crime, autoritarismo. Discute-se as implicações dos resultados à luz dos estudos decoloniais em uma interlocução entre autores como Hannah Arendt e Crochik, além de teóricos pós-coloniais, como Mbembe, Spivak e Martin-Baró.

Palavras-chave: Interseccionalidade, Autoritarismo, Medo, Raça, Classe. 


\title{
Intersectional Analyses from Race and Class: Fear of Crime and Authoritarianism in Brazil
}

\begin{abstract}
The present study aimed to present, from a quantitative intersectional analysis, the extent to which race / class markers interfere in the fear of crime and authoritarianism in the Brazilian context. 2,087 people from all regions of the country participated in a representative sample of the Brazilian population, mostly aged 25-34 years (26.3\%), blacks $(60.0 \%)$ and belonging to the D / E class (27,3\%), having responded to the Adorno Scale F (version 17 items) and scales to measure fear, victimization and the chances of crimes occurring. Variance analyses did not indicate significant differences between breeds for authoritarianism ( $F=2.60$ and $\mathrm{p}=0.017$ ), when the effects of the classes were not considered. However, there was a significant difference between classes $(\mathrm{F}=14.265(\mathrm{p}<0.001)$, mainly among whites $(\mathrm{F}=11.08$ and $\mathrm{p}<0.05)$, while in the comparison for blacks and whites in specific classes, only in stratum B1 there was a significant difference $(\mathrm{F}=4.54, \mathrm{p}<=0.05)$ High levels of fear of crime appear at all race / class intersections, notably Class A blacks $(\mathrm{F}=6.52, \mathrm{p}<=0.05)$ From the discriminant analysis, two profiles of groups with greater and lesser fear of crime were formed based on factors such as gender, age, race, class, chances of suffering crime, authoritarianism. Results are discussed in light of decolonial studies in a dialogue between authors such as Hannah Arendt and Crochik, as well as postcolonial theorists like Mbembe, Spivak and Martin-Baró.
\end{abstract}

Keywords: Intersectionality, Authoritarianism,Fear, Race, Class.

\section{Análisis Interseccionales a partir de la Raza y de la Clase: Miedo del Crimen y Autoritarismo en Brasil}

Resumen: El presente estudio objetivó presentar, a partir de un análisis interseccional cuantitativo, en qué medida los marcadores de raza / clase interfieren en el miedo del crimen y en el autoritarismo en contexto brasileño. Participaron 2.087 personas de todas las regiones del país, en una muestra representativa de la población brasileña, mayoritariamente con edades entre 25 y 34 años (26,3\%), negros (60,0\%) y pertenecientes a la clase D/E (27, 3\%), habiendo respondido a la Escala F de Adorno (versión 17 ítems) y escalas para medir el miedo, la victimización y las posibilidades de ocurrencia de crímenes. Los análisis de varianza no indicaron diferencias significativas entre razas para el autoritarismo $(F=2,60$ y p $=0,017$ ), cuando no se considera el efecto de las clases. Sin embargo, hubo una diferencia significativa entre las clases $(\mathrm{F}=14,265$ ( $\mathrm{p}<=0,001)$, principalmente entre los blancos $(\mathrm{F}=11,08$ y p $<0,05)$. Mientras que en la comparación para negros y blancos en clases específicas, solo en el estrato B1 $(\mathrm{F}=4,54, \mathrm{p}<=0,05)$. Niveles elevados de miedo al crimen aparecen en todas las intersecciones de raza clase, destacadamente entre los negros de clase A $(F=6,52, p<=0,05)$. A partir del análisis discriminante, dos perfiles de agrupaciones con mayor y menor temor al crimen fueron formados a partir de factores como género, edad, raza, clase, posibilidades de sufrir crimen, autoritarismo. Se discuten las implicaciones de los resultados a la luz de los estudios decoloniales en una interlocución entre autores como Hannah Arendt y Crochik, además de teóricos post-decoloniales, como Mbembe, Spivak y Martin-Baró.

Palabras clave: Interseccionalidad, Autoritarismo, Miedo, Raza, Clase. 


\section{Introdução}

Há o crescimento de posições autoritárias relacionadas ao medo da violência no Brasil de acordo Fórum Brasileiro de Segurança Pública (2017). Neste relatório, também é apontado a relevância de se estudar o autoritarismo, especialmente, considerando o contexto sócio-político brasileiro. De acordo com Waiselfisz (2016), há um processo de recrudescimento da violência principalmente referente aos homicídios de determinadas parcelas da população. Segundo o Atlas da Violência, há um significativo aumento dos índices de homicídios principalmente para homens e mulheres negras (Cerqueira et al., 2018). Concebe-se, assim, a necessidade de avançar de forma interseccional na análise da origem da violência como vinculada a um traço autoritário e colonial presente na sociedade brasileira. Martín-Baró (2017) traz a necessidade de examinar a violência a partir da perspectiva histórica, como também de compreender suas consequências vinculadas a gestão do medo como uma estratégia manutenção da desigualdade social. Assim, tem-se como objetivo apresentar, a partir de uma análise interseccional quantitativa, em que medida os marcadores de raça/classe interferem no medo do crime e no autoritarismo em contexto brasileiro

Nesse sentido, cabe às reflexões interseccionais acerca dos marcadores de raça e classe que se relacionam e se destacam na produção de desigualdades, impactando o acesso qualificado à saúde, educação, emprego e renda, justiça etc, que são relevantes para a discussão sobre segurança pública (IBGE, 2017; 2018; Rocha, 2015). Além disso, há um fator gestão do medo, pois a mídia traz constantes notícias sobre os índices de violência no país, fortalecendo um sentimento de medo do crime e de insegurança nas populações das cidades. Há um questionamento sobre a eficácia das políticas públicas de insegurança, promovendo um cenário de crise que favorece o apoio da população a posições mais autoritárias e abordagens policiais mais ostensivas, que por vezes, se findam em mortes de suspeitos e civis não envolvidos em conflito. Estes são, na grande maioria das vezes, pobres, jovens, homens e negros (Noronha, \& Paes-Machado, 2013).

Assim, é a população negra e pobre que possui a maior prevalência de transtornos mentais graves e comuns, de vitimização por homicídio e outros crimes violentos, de morbidade e mortalidade, entre outros aspectos (Cerqueira et al., 2018; Smolen,
\& Araújo, 2017; Williams, \& Priest, 2015). Um dos desdobramentos mais graves dessas desvantagens é a sobrerrepresentação sociorracial no sistema penitenciário, cuja população é majoritariamente composta por negros pobres (Brasil, 2017). Apesar dessa desigualdade marcante, quanto à raça, há uma tentativa de invisibilização das tensões raciais fundamentada no mito da democracia racial (ou seja, a alegação de que a intensa miscigenação produziu relações raciais pacíficas) (Zamora, 2012). De forma semelhante, quanto à classe, o isolamento e a pauperização de certas camadas sociais é aprofundada pela associação da acumulação ou escassez de riquezas com qualidades e defeitos pessoais intrínsecos (Accorssi, Scarparo, \& Guareschi, 2012; Moura Junior, \& Ximenes, 2016). Portanto, no Brasil, os cruzamentos de raça e de classe são fundamentais para a compreensão das disparidades. Uma abordagem interseccional permite uma maior compreensão dos processos de discriminação e exclusão a partir das conexões raça-classe e, consequentemente, um melhor enfrentamento das múltiplas e distintas opressões (Crenshaw, 2002).

Dessa forma, a gestão da violência por meio do autoritarismo e sua consequência concretizada pelo sentimento de medo podem impactar de forma específica a partir de uma análise interseccional entre os marcadores de raça/classe. Assim, o manuscrito está estruturado da seguinte forma; na primeira parte propõe discutir sobre segurança pública e o contexto brasileiro. O segundo tópico examina o autoritarismo tomando como base seu conceito, suas implicações e causas e o medo do crime a partir de um olhar da Psicologia Social dialogando com a discussão interseccional e pós-colonial. Na segunda parte, é apresentado o percurso do método desenvolvido e, em seguida, são discutidos os resultados do agenciamento de autoritarismo e medo do crime com os marcadores interseccionais e seus efeitos de desigualdade social produzidos no lócus da pesquisa, considerando a relevância destes para as políticas de segurança pública.

\section{Segurança Pública e suas implicações do contexto brasileiro}

O debate da segurança pública desde o século XIX tem propiciado campos de investigação e produção do conhecimento, uma vez que os estudos criminais cresceram em virtude do aumento da criminalidade e dos desafios cotidianos de enfrenta- 
mento desse problema. Vale ressaltar a forma caótica como as mídias têm retratado a segurança pública na contemporaneidade à favor de uma ordem social operada para dispor das desigualdades sociais. Esta concepção tem fortalecido a produção da relação causal que naturaliza os indivíduos em seus marcadores desiguais, ou seja, o negro, o pobre, o marginalizado sempre como o criminal, de tal forma que o comportamento criminoso se tornou o disparador de combate individualizante do crime, em vez de repensar como problemas estruturantes mais complexos (Bicalho, Kastrup, \& Reishoffer, 2012).

Para Reishoffer e Bicalho (2009), o contexto histórico da formação política e de segurança pública no Brasil tem raízes que produzem efeitos até o presente, visto que o marco do regime ditatorial e a constituição de 1988 refletem numa díade de sistemas e estruturas policiais e legislativas que trazem à tona minimamente retratos de uma lógica militarizada de combate à criminalidade sob a imagem do "inimigo interno". Essa última concepção tem raízes na ideologia instaurada pela ditadura no combate ao sujeito que desafiava a nação e ao progresso do país, perceptível nos sujeitos classificados como perigosos e excluídos da participação social mantida pela elite e pelos militares.

Noronha e Paes-Machado (2013) em um estudo com policiais relatam que estes profissionais acabam associando os marcadores de criminalidade e o de pobreza, tendo mudanças de posturas quando atuam em áreas mais pobres. Nesses contextos, a abordagem é mais truculenta, gerando uma suposição de que há mais ações violentas e crimes nos locais mais pobres. Ocasionam-se, assim, mais mortes de pessoas, não necessariamente envolvidas, sem responsabilização e/ou especificação da autoria. Destaca-se também, segundo Paes-Machado e Noronha (2002), o reconhecimento que a polícia ao atuar em áreas mais pobres, possui uma atuação mais autoritária como forma de demonstrar sua capacidade de ação e poder frente às populações destas áreas. Estas são encaradas a partir de seus marcadores (raça/classe/gênero) e postas no lugar de permanente suspeição, despertando a estas o temor e fortalecendo o estereótipo social da institui- ção como amedrontadora. A polícia geralmente age mostrando seu poder de ação e de retaliação, tendo um conceito de autoritarismo fortemente relacionado a força letal.

Por outro lado, estes também sofrem algum tipo de discriminação à medida que o policiamento ostensivo é composto por maioria de negros e advindos de classes sociais mais empobrecidas. Por vezes, a abordagem truculenta e violenta infligida às populações mais pobres é relacionada com suas origens, com uma concepção igualmente criminalizadora e discriminatória da pobreza. Assim, imbuem-se a estes o despreparo cultural para utilizar uma linguagem não violenta, como se estes fossem os responsáveis exclusivos pelas práticas violentas da polícia. Para tanto, estes policiais subalternos são os mais tentados a demonstrar poder, por meio do uso excessivo da força, junto às populações mais pobres (Noronha, \& Paes-Machado, 2013).

Schwartzman (2007) afirma que o autoritarismo no Brasil possui raízes profundas, tendo implicações que não se desfazem apenas por rearranjos das instituições, pensando que ele não emerge em apenas um acontecimento histórico, como a ditadura militar de 64, fortemente marcada pelo autoritarismo, e não se finda com a passagem desses acontecimentos, não sendo um fenômeno passageiro. Contudo, para além de uma análise fatalista, concebe-se que reconhecer historicamente e encarar este fenômeno é crucial para a construção de estratégias de enfrentamento (Martín-Baró, 2017).

\section{Discutindo autoritarismo e o medo do crime sob a perspectiva da Psicologia Social e Pós-colonial}

Os trabalhos pioneiros acerca do autoritarismo emergiram através das pesquisas sobre personalidade autoritária que tiveram grande destaque a partir dos estudos desenvolvidos por Theodor Adorno e outros colaboradores a partir de 1950 com a criação da Escala F (Fascismo) ${ }^{1}$ que possuiu o objetivo de medir a personalidade individual potencialmente fascista ${ }^{2}$. Isso foi possível em decorrência dos estudos realizados pelo Instituto de Pesquisa em Psicologia Social na Ale-

\footnotetext{
${ }^{1}$ A Escala F pode ser consultada em íntegra na obra original intitulada “The Authoritarian Personality” (Adorno, Brunsvik-Frenkel, Levinson, \& Sanford, 1950). Esta mesma obra não possui tradução para o português, isto é, ao longo do corpo textual as citações decorrentes desta obra foram traduzidas pelos autores deste manuscrito.

${ }^{2}$ Tradução da obra original de Adorno et al. (1950): "potentially fascistic individual".
} 
manha, porém a criação, mensuração e publicação da escala ocorreu nos Estados Unidos na Universidade de Berkeley na Califórnia.

Como aponta Crochik (2017), a escala possibilitou alavancar várias discussões sobre a personalidade autoritária suscetível ao fascismo após os desastres sociais da Segunda Guerra Mundial e o holocausto do nazismo. No entanto, o objetivo não se reduziu aos números ou análises psicométricas da escala. Por outro lado, a mensuração irredutível dos dados em análises mais subjetivas propiciou que diversos métodos e discussões fossem gerados pela academia científica sobre ideologia, conservadorismo político, preconceito e fascismo.

Assim, para entender a personalidade autoritária, deve-se compreender que a consciência é atravessada pelas mediações pela qual o ser humano é interpelado, seja pela via da racionalidade crítica ou até mesmo por uma irracionalidade que se concebe em uma consciência ignorante que impossibilita o sujeito fazer atos em prol do bem-estar social (Crochik, 2017). Essa consciência, segundo Adorno e Horkheimer (2006, p.45), é concebida como um produto da opressão recorrida pela burguesia para atingir o poder a partir de "o desencadeamento das forças, a liberdade universal, a autodeterminação, em suma, o esclarecimento". Nesse contexto, o esclarecimento recai sobre a mesma utopia que o conceito de razão. Este é o produto da consciência que habilita a capacidade judicativa dos homens no discernimento de suas ações. Assim, a burguesia como substrato social dominante se apropria da razão em sua condição mais hostil e elimina o que julga em desacordo com a ordem social em curso.

Nesse ínterim, a manutenção pela qual a dominação ocorre é concretizada por uma "gestão de comportamentos" (Crochik, 2017, p. 51). E tem como base representações de líderes. Isto é, o regime de opressão é político, ideológico e organizado, e por isso, o líder inaugura modos de vida de acordo com sua soberania autocrática de visão de mundo. Assim, a violência desses regimes poderia ser analisada quando compreendida a vulnerabilidade. Esta é negada arbitrariamente em busca de proteção das elites. Ou seja, os sujeitos elencados mais vulneráveis são perseguidos e tendem a ser eliminados como condição de manutenção dos regimes totalitários (Crochik, 2017). De acordo com Martín-Baró (2017), o medo é uma ferramenta utilizada pelas elites para propagar a ideia de inimigo comum como estratégia de permanência no poder. Com a gestão da violência, esse medo é propagado nos diferentes estratos sociais, mas é importante salientar que a classe que é historicamente dizimada é a mais pobres que, no Brasil, intersecciona-se com a população negra.

Segundo Crochik, Casco, Ceron e Catanzaro (2009), o fenômeno do autoritarismo é visto como produto de estranheza do movimento ideológico que se entrelaça a uma racionalidade que tem efeitos no campo econômico, social e político, dentre outros. Desse modo, o fortalecimento de ideologias que operam contra uma racionalidade de bem-estar coletivo se mantém no combate ao que é hostil, ao que é frágil, vulnerável, e por último diferente. Estas são vistas como ideologias irracionais e não são produtos de uma consciência individualizada, mas constituídas pelo presente histórico e captadas pelos sujeitos - principalmente pela via do psíquico. E o preconceito assume, então, uma síntese da ideologia fascista como dominação das categorias de "minorias" (2009, p. 125).

Nessa perspectiva, a análise da conjuntura social deve incluir desde experiências comuns a um grupo minoritário que compartilha apenas um aspecto, como a raça, até experiências singulares de discriminação vividas por grupos que compartilham mais de uma característica, como a raça e a classe. Ser negro e estar em situação de pobreza, individualmente representam distintas opressões que se somam e cruzam nos indivíduos que acumulam essas características. Os negros pobres podem, respectivamente, vivenciar experiências de opressão similares a brancos pobres e a negros ricos/classe média (abordagem de eixo único); vivenciar uma dupla penalização de efeitos cumulativos nas experiências de opressão (abordagem aditiva); e, por fim, uma opressão específica, baseada na intersecção da sua raça e classe (abordagem interseccional) (Crenshaw, 2002).

É seguindo o rumo de uma base autoritária que a sociedade brasileira tem se estruturado. Historicamente, a população negra e indígena tem sido dizimada de maneira concreta e epistêmica por conta do processo de colonização e da divisão racial do mundo ocidental (Quijano, 2005). Há, assim, o desenvolvimento de formas de vida que não são reconhecidas como humanas, podendo ser executadas, torturadas e escravizadas a partir da criação da ideia falaciosa de raça (Grosfoguel, 2016). Esse sistema escravagista foi marcante para desenvolvimento da sociedade, mas 
também o período pós-abolição formou uma classe pobre que era/é eminentemente negra, interseccionando a questão racial e de classe no Brasil de forma mais evidente (Bernardino-Costa, 2015).

Portanto, há o fortalecimento de normativas preconceituosas e excludentes de minorias(maiorias), as quais historicamente não têm acesso à rede de consumo de bens. Dentro dessa realidade é que se forjam campos minados de violência, desordem e extermínio das classes desfavorecidas que são em sua maioria negra (Reishoffer, \& Bicalho, 2009). Assim, é no debate pós-colonial sobre essas tensões excludentes de indivíduos a partir da raça e classe que podemos refletir sobre a realidade social, pois, no berço da colonialidade a formação do sujeito colonial é também um sujeito subalterno. É sobretudo uma subalternidade que se afirmou na obediência autoritária dos regimes de legalidade e da cultura eurocêntrica. Com isso, o projeto de expansão da cultura europeia movida pelo projeto imperialista se sustentou e persevera a partir das modificações históricas em exclusões como a da mulher, pobre, negro(a), e de outros indivíduos (Spivak, 2010). Estes, por sua vez, reconhecidos em sua humanidade como periféricos, sendo violados e esquecidos pelo regime apartheid que produziu colonizações nos países mais pobres (Crenshaw, 2002).

\section{Método}

\section{Participantes}

O estudo foi realizado a partir do banco de dados da pesquisa "Medo da Violência e o Apoio ao Autoritarismo no Brasil” desenvolvida pelo Fórum Brasileiro de Segurança Pública em parceria com universidades públicas. Ela envolveu 2.087 pessoas de todas as regiões do país, em uma amostra estatisticamente representativa da população brasileira. A maioria dos participantes tinham entre 25 e 34 anos $(26,3 \%)$, eram do gênero feminino $(50,8 \%)$, negros $(60,0 \%)$, da região Sudeste $(42,5 \%)$, com renda individual mensal inferior a dois salários mínimos (69,6\%) e da classe D/E (27,3\%).

\section{Instrumentos}

Foi utilizado a Escala $\mathrm{F}$ de Adorno versão 17 itens (EF-A, $\alpha=0,82$ ) (Fórum Brasileiro de Segurança Pública, 2017). Essas assertivas são relacionadas à submissão e agressividade autoritária e à defesa de valores e instituições convencionais ou conservadoras (por exemplo, "O que este país necessita, principalmente, antes de leis ou planos políticos, é de alguns líderes valentes, incansáveis e dedicados em quem o povo possa depositar a sua fé"; "A maioria de nossos problemas sociais estaria resolvida se pudéssemos nos livrar das pessoas imorais, dos marginais e dos pervertidos"). As respostas indicam o grau de concordância por meio de uma escala Likert que varia de 1 (Discordo totalmente) a 6 (Concordo totalmente), sem ponto neutro.

Além disso, foram utilizadas escalas para mensurar o medo, a vitimização e as chances de ocorrência de crimes. A escala de medo do crime foi composta por 16 itens referentes ao medo de ser vítima de algum delito (por exemplo, Você diria que tem medo de: "Morrer assassinado", "Ter o celular furtado ou roubado"), respondidos por meio de uma escala Likert que três pontos $(1=$ Nenhum medo; $2=$ Pouco medo; 3 = Muito medo). Já a escala de vitimização do crime foi composta por 15 assertivas referente à quais tipos de crime o participante havia sido vítima no último mês (os mesmos itens da escala de medo do crime, menos o item referente à vitimização por homicídio), respondidas com sim ou não. E ainda, a escala de chances de ocorrência de vitimização por crime, composta por 16 itens referentes à probabilidade de o indivíduo sofrer algum delito no próximo mês (por exemplo, "Morrer assassinado", "Ter o celular furtado ou roubado"), respondidos por meio de uma escala Likert variando de 0 (Nenhuma chance de acontecer) a 10 (muita chance de acontecer).

Por fim, para mensurar a classe foi utilizado o Critério Brasil de classes (Associação Brasileira de Empresas de Pesquisa - ABEP, 2017). Para compor os estratos (A, B1, B2, C1, C2, D/E) as questões levam em consideração o acesso à bens e serviços (por exemplo, eletrodomésticos, banheiros, empregados), à água e esgotamento sanitário, e ainda, às condições do trecho da rua do domicílio e à escolaridade do principal responsável da família. Para possibilitar as comparações entre grupos, foram incluídas questões sociodemográficas, como raça autodeclarada, gênero, idade etc.

\section{Procedimentos}

A pesquisa foi realizada pelo Instituto Datafolha no primeiro semestre de 2017, sendo coordenada pelo Fórum Brasileiro de Segurança Pública e profes- 
sores de diferentes Instituições Públicas de Ensino Superior. Ela está relacionada a um projeto de pesquisa aprovado pelo comitê de ética de uma universidade pública. Os procedimentos de coleta de dados foram baseados em critérios de representatividade, estratificação e aleatoriedade de acordo com a atualização dos dados populacionais brasileiros a partir do censo de 2010 realizado pelo Instituto Brasileiro de Geografia e Estatísticas. Assim, foram realizadas visitas domiciliares com a aplicação do questionário da investigação.

Sobre os procedimentos de análise, tendo em vista a sobre representação de raça e de gênero em algumas das classes, foram excluídos aleatoriamente 442 sujeitos para equilibrar a quantidade de pessoas nos grupos (A, B1, B2, C1, C2, D/E). Dessa forma, permaneceram 1642 participantes com idades média de 39 anos $(\mathrm{DP}=16,3)$, sendo 893 da raça negra $(54,4 \%)$ e 749 da raça branca (45,6\%), distribuídos em 831 homens (50,6\%) e 811 mulheres (49,4\%). Assim, foram realizadas ANOVAs para comparar os grupos dentre e entre raças e classes quanto aos níveis de autoritarismo e de medo do crime.

Além disso, conduziu-se uma Análise Discriminante visando identificar os perfis discriminantes dos grupos com maior e menor medo do crime em relação aos fatores potencialmente influenciadores do medo. Essa análise foi utilizada com o objetivo de maximizar as diferenças entre esses fatores nos dois grupos (maior e menor medo), contribuindo para identificar a diferenciação entre os indivíduos de cada um dos grupos. Dessa forma, optou-se por excluir 598 sujeitos, permanecendo o terço superior e o inferior na pontuação da escala. Foi utilizado o método stepwise, em que cada variável independente é inserida na função discriminante uma por vez, com base em seu poder discriminatório.

\section{Resultados e discussão}

É relevante neste estudo a constituição de uma amostra representativa da população brasileira e sua percepção acerca do autoritarismo e do medo do crime que tem crescido de forma significativa (Fórum Brasileiro de Segurança Pública, 2017). Como mencionado, utilizaremos os marcadores de raça e classe para realizar essa leitura. Isso porque, é necessário compreender o fenômeno do autoritarismo sobre um viés interseccional, pois uma análise dos marcadores de raça e classe dissociados não consegue dar conta do fenômeno.

A maior parcela da população brasileira se autodeclara negra (pretos e pardos), concentrando-se nas classes mais empobrecidas (Zamora, 2012). Nesse sentido, é importante destacar que o fenômeno do racismo no Brasil tem uma conjuntura muito particular, pois se constitui de forma cordial (Lima, \& Vala, 2004). Há uma dificuldade de assumir sua existência e, concomitantemente, ocorre um processo de invisibilização dos casos de racismo. É com base em um discurso de que a população passou por um processo forte de miscigenação que se tenta justificar uma falaciosa inexistência do racismo no país (Bento, 2009).

Como se pode observar na Tabela 1, quanto à comparação do autoritarismo para negro e brancos, independentemente da classe, por meio de Análise de Variância (ANOVA), não ocorreram diferenças significativas $(F=2,60 ; p=0,107)$. Dessa forma, o efeito do autoritarismo no que confere à raça isoladamente aponta para a necessidade de uma análise mais profunda que contextualize outras questões. Já quanto à comparação entre os sujeitos de todas as classes, independentemente da raça, houve diferença significativa nos níveis de autoritarismo ( $\mathrm{F}=14,265$ ( $\mathrm{p}<=0,001$ ), sendo gradativamente maior desde as classes mais abastadas, como A e B1 ( $\mathrm{M}=3,90 ; \mathrm{DP}=0,85 ; \mathrm{M}=4,08$; $\mathrm{DP}=0,77$, respectivamente), até as mais pobres, como $\mathrm{C} 2$ e D/E (M = 4,44; $\mathrm{DP}=0,61 ; \mathrm{M}=4,51 ; \mathrm{DP}=0,67$, respectivamente). Ou seja, a classe é um marcador que influencia fortemente os níveis de concordância com posicionamentos autoritários.

Considerando as desigualdades raciais e socioeconômicas brasileiras, entendemos que as desigualdades raciais não podem ser reduzidas ao marcador classe embora se articulem com estas (Zamora, 2012). Assim, para investigar a intersecção desses marcadores, realizaram-se comparações específicas dos níveis de autoritarismo entre classes para negros e brancos, ambas resultaram significativas, mais preponderante para brancos $(\mathrm{F}=11,08 ; \mathrm{p}<=0,001)$ do que para negros ( $\mathrm{F}=4,62 ; \mathrm{p}<=0,001)$. Indicando então, uma menor influência da classe sobre os níveis de autoritarismo entre os negros.

Nesse sentido, Zamora (2012) considera que o fenômeno do racismo como um operador social que favorece o entendimento da sociedade e da produção de subjetividades como posições autoritárias. É capaz de agregar indivíduos e grupos por certos aspectos 
fenótipos e determinar atitudes negativas frente a estes, visibilizando formas de exercício de poder das classes dominantes, frente aos dominados. Então um dos efeitos do racismo pode ser essa maior influência do poder econômico nos níveis de autoritarismo de indivíduos brancos. O que se relaciona intrinsecamente com o processo de colonialidade vivenciado no nosso contexto.

Fanon (2008) pontua que o processo de colonialidade faz parte do imperativo da dominação e discriminação daqueles que são subjugados como inferiores. Há um processo de inferiorização que não está situado nos indivíduos mais privilegiados, mas que pode ser internalizado e reproduzido pelos sujeitos discriminados. Ocorre a vivência da dualidade do não ser, tanto da dimensão da diferença do lugar do privilégio, como do não se reconhecer como outro. Existe, então, um processo de identificação com aquele que é objeto que suscita medo e terror.

Ainda sobre essa realidade histórica a luz do Mbembe (2017), essa colonialidade fez emergir uma produção de extermínio do homem contra o homem que não foi simplesmente dada nem tão pouco inata de uma condição natural, mas é perpassado por um processo de construção do "medo". Este, desde os primórdios da colonização dos países, esteve associado ao mito do fim do homem e, por conseguinte, do mundo. Assim, para o dominante, esta condição de diferenciação entre estes, que podem viver, e outros que são passíveis de serem mortos instaura um processo de violência racial e colonial. O outro (não dominante) torna-se responsável por suscitar a própria violência, pois a sua sobrevivência é mediada pelos processos de subjetivação de dominação e/ou de extermínio.

Quanto à comparação do autoritarismo entre raças para cada uma das classes os resultados das ANOVAs indicaram diferenças significativas apenas para $\mathrm{B} 1(\mathrm{~F}=4,54 ; \mathrm{p}<=0,05)$, onde negros apresentaram média de 4,24 e os brancos 3,94 (Tabela 1). Portanto, apesar de em geral, os negros apresentarem médias um pouco maiores do que os brancos, apenas nesse estrato específico há uma diferença significativa. O que indica uma maior influência do marcador de classe para os níveis de autoritarismo das classes mais abastadas. Classes estas que, ao acumular recursos em um país desigual e tomado pelo medo do crime, se posicionam de forma autoritária e propagam para as classes menos abastadas esses seus interesses individuais (Martín-Baró, 2017).

Já nos resultados encontrados com as comparações de grupos acerca do medo do crime (Tabela 2), os sujeitos de todas as classes apresentaram níveis elevados de medo do crime. Não houve diferenças significativas entre as raças ou entre as classes quando consideradas isoladamente. Apenas a comparação de classes dentre negros apresentou resultado significativo, porém fraco $(\mathrm{F}=2,20 ; \mathrm{p}<=0,05)$. Destaca-se que, analisando interseccionalmente a classe $\mathrm{A}$, negros $(\mathrm{M}=2,35$; $\mathrm{DP}=0,50)$ e brancos ( $\mathrm{M}=2,17$; $\mathrm{DP}=0,49)$ apresentaram diferença significativa $(F=6,52 ; p<=0,05)$, em que a população negra de classe A possui um nível consideravelmente maior de medo do crime.

Tabela 1.

Médias de autoritarismo por grupos.

\begin{tabular}{|c|c|c|c|c|c|c|c|c|c|c|}
\hline \multirow{2}{*}{ Classes } & \multicolumn{3}{|c|}{ Negro } & \multicolumn{3}{|c|}{ Branco } & \multicolumn{3}{|c|}{ Total } & \multirow{2}{*}{$\begin{array}{c}\text { ANOVA } \\
\mathrm{F} \\
\end{array}$} \\
\hline & Média & $\mathrm{DP}$ & $\mathrm{N}$ & Média & DP & $\mathrm{N}$ & Média & DP & $\mathrm{N}$ & \\
\hline A & 4,13 & 0,85 & 28 & 3,75 & 0,92 & 42 & 3,90 & 0,85 & 70 & 3,34 \\
\hline B1 & 4,24 & 0,68 & 58 & 3,94 & 0,83 & 59 & 4,08 & 0,77 & 117 & $4,54^{*}$ \\
\hline B2 & 4,20 & 0,72 & 202 & 4,25 & 0,74 & 168 & 4,23 & 0,73 & 370 & 0,49 \\
\hline $\mathrm{C} 1$ & 4,38 & 0,70 & 252 & 4,24 & 0,86 & 200 & 4,32 & 0,78 & 452 & 3,35 \\
\hline $\mathrm{C} 2$ & 4,43 & 0,58 & 197 & 4,46 & 0,66 & 165 & 4,44 & 0,61 & 362 & 0,26 \\
\hline $\mathrm{D} / \mathrm{E}$ & 4,48 & 0,64 & 156 & 4,56 & 0,71 & 115 & 4,51 & 0,67 & 271 & 0,94 \\
\hline Total & 4,35 & 0,67 & 893 & 4,29 & 0,79 & 749 & 4,32 & 0,73 & 1.642 & 2,60 \\
\hline ANOVA & \multicolumn{3}{|c|}{$\mathrm{F}=4,62^{* *}$} & \multicolumn{3}{|c|}{$\mathrm{F}=11,08^{* *}$} & \multicolumn{3}{|c|}{$\mathrm{F}=14,26^{* *}$} & - \\
\hline
\end{tabular}

${ }^{*} \mathrm{p}<=0,05$.

** $\mathrm{p}<=0,001$. 
Tabela 2.

Média de medo do crime por grupo.

\begin{tabular}{lcccccccccc}
\hline \multirow{2}{*}{ Classes } & \multicolumn{3}{c}{ Negro } & \multicolumn{3}{c}{ Branco } & \multicolumn{3}{c}{ Total } & \multicolumn{2}{c}{ ANOVA } \\
\cline { 2 - 10 } & Média & DP & N & Média & DP & N & Média & DP & N & F \\
\hline A & $\mathbf{2 , 3 5}$ & $\mathbf{0 , 5 0}$ & $\mathbf{2 8}$ & $\mathbf{2 , 0 4}$ & $\mathbf{0 , 4 9}$ & $\mathbf{4 2}$ & $\mathbf{2 , 1 7}$ & $\mathbf{0 , 5 1}$ & $\mathbf{7 0}$ & $\mathbf{6 , 5 2}^{*}$ \\
B1 & 2,18 & 0,53 & 58 & 2,13 & 0,62 & 59 & 2,15 & 0,58 & 117 & 0,22 \\
B2 & 2,20 & 0,53 & 202 & 2,16 & 0,58 & 168 & 2,18 & 0,55 & 370 & 0,45 \\
C1 & 2,22 & 0,59 & 252 & 2,18 & 0,62 & 200 & 2,21 & 0,59 & 452 & 0,45 \\
C2 & 2,34 & 0,53 & 197 & 2,25 & 0,53 & 165 & 2,30 & 0,53 & 362 & 2,26 \\
D/E & 2,31 & 0,56 & 156 & 2,21 & 0,62 & 114 & 2,27 & 0,59 & 270 & 1,94 \\
Total & 2,26 & 0,55 & 893 & 2,19 & 0,58 & 748 & 2,23 & 0,56 & 1.641 & 7,06 \\
ANOVA & & $\mathbf{F = 2 , 2 0 *}$ & & & $\mathbf{F = 1 , 1 6}$ & & & $\mathbf{F = \mathbf { 2 , 6 5 }}$ & - \\
\hline
\end{tabular}

${ }^{*} \mathrm{p}<=0,05$.

Por fim, a Análise Discriminante permitiu traçar dois perfis a partir dos agrupamentos com maior e menor medo do crime, a partir de fatores potencialmente influentes, como gênero, idade, raça, classe, chances de sofrer crime, autoritarismo e vitimização. Utilizando o método stepwise foi identificada uma função significativa $(\mathrm{p}<0,001)$ e com um autovalor de 0,451 , formada por essas características exceto a vitimização. Verificou-se ainda, uma correlação canônica de 0,558 entre perfil e função. O Wilk's Lambda informou que com essa função é possível explicar 68,9\% (1-Wilks) da variância existente entre os grupos. Além disso, há uma excelente capacidade de predição em que $77,7 \%$ do grupo com menos medo está bem discriminado. E 71,9\% do grupo com mais medo também está bem discriminado nas funções existentes. Foi identificada somente uma função discriminante em que o grupo com menos medo possui o centroide - 0,723 e o grupo com mais medo tem o centroide 0,623 . A partir dessa função discriminantes, destacaram-se as seguintes variáveis mais vinculadas ao grupo com mais medo: chances de vitimização $(0,771)$, gênero $(0,468)$, classe $(0,190)$, autoritarismo $(0,184)$, vitimização $(0,164)$, raça $(0,122)$. A única variável que se relacionou de forma leve com o grupo menos medo foi a idade $(-0,173)$.

Nesse sentido, os dados retratam uma realidade vivida no Brasil em que, os últimos anos, foram marcados pela polarização dos discursos político-ideológicos, que levaram à ocorrência de violência e intolerância em detrimento do debate de ideias. Destacando-se narrativas baseadas em um salvacionismo autoritário e elitista, que propaga a segregação, a marginalização, a exclusão e a eliminação de minorias (Souza, 2017). O medo dentro dos estudos pós-coloniais pode ser analisado como ferramenta em que as elites se apropriaram meticulosamente para a perpetuação/formação das desigualdades sociais, uma vez que essa realidade é fortemente desdobrada na formação das sociedades nos países do hemisfério sul. Entende-se que esse medo é a própria sensação de insegurança engendrada na vida social, logo porque possibilita que sejam legitimadas as exclusões e segregações sociais (Martin-Baró, 2017).

Essa perpetuação da violência com mais casos de vitimização e do medo tem servido como estratégia de controle de populações, que acabam sustentando os ideários político-ideológicos autoritários das elites e, contraditoriamente, se contrapondo a políticas de equidade. Pessoas situadas em pontos de interseções raça-classe estão mais expostas à violência e ao medo (por exemplo, negros, pobres, baixa escolaridade, habitantes da região nordeste) tendem a apoiar posições autoritárias mais do que aquelas com acesso privilegiado a recursos econômicos e culturais (Fórum Brasileiro de Segurança Pública, 2017)

Entende-se também que a questão da violência a partir das chances de vitimização está presente direta e indiretamente no cotidiano das populações negras e pobres, em suas relações familiares, comunitárias e institucionais, e é construída e mantida por meio da conservação de padrões assimétricos nas relações de gênero, raça, classe e geração (Maranhão, Colaço, Santos, Lopes, \& Coêlho, 2014). Atualmente, a principal forma de estratégia de gestão desses grupos sociais é, por um lado, o recrudescimento do Estado penal e a 
exposição às violências e, por outro, o abandono de políticas de bem-estar social (Wacquant, 2001).

Reishoffer e Bicalho (2009) ratificam o contexto neoliberal como um campo político no qual a violência urbana é capturada pelo capitalismo. Isto acontece, porque a criminalidade produz demanda de novas empresas especializadas em vigilância, novos centros formativos de policiais, dentre outras coisas. Assim, a insegurança e o medo são capturados e agenciados para a produção de desejo de cada vez mais segurança. É nesse contexto que as desigualdades podem ser postas em xeque quando a burguesia é a fonte econômica de embolso - capital dessa realidade, ficando para a periferia a divisão forte da exclusão desse direito securitário.

Em meio a esses processos de coação, para potencializar seus efeitos, são bombardeados por programas que transformam o crime em espetáculo, criando e fortalecendo o medo. Dessa forma, pautado na tríade crime, medo e violência, são impelidas a aceitar e propagar posicionamentos autoritários tipicamente elitistas. Há apoio de uma grande parcela da população a ideologias mais autoritárias, que fazem emergir aceitação por parte dessas populações de políticas mais violentas e excludentes. Mbembe (2017) considera essa tendência como política da inimizade onde se fortalece a figura ficcional de um inimigo que precisa ser combatido, e exterminado, e para isso justifica-se o uso de violência e da militarização da vida contra esses não-sujeitos.

Nesse contexto de construção de segurança pública brasileira, a mídia como comunicação de massa foi importante no papel de veicular a imagem de inimigo interno, porque produziu fontes que minimamente propagaram discursos que tinham o enaltecimento da democracia e dos direitos humanos na mesma medida que as classes perigosas eram reprimidas. Esse movimento de segurança pública teve dois lados da mesma moeda, de um lado a militarização da polícia com a repressão ostensiva e uso da força para implementar a ordem e o controle do caos criminal, e do outro lado o discurso imaginário de sujeito cidadão com políticas atentas aos pilares democráticos de direitos humanos (Reishoffer, \& Bicalho, 2009).
Desse modo, o medo que é produzido se alia veemente com a distinção racial operada nessas colônias, que se mostra na distinção de que a vida do selvagem (negro, escravo, pobre, colonizado etc.) é apenas uma forma de vida animal outra. Então, o colonizador ao não reconhecer o outro como humano coloca-o numa posição outra de um não humano, de um não importante, de uma não vida e por assim dizer, de dominado, de escravizado, de inferior e de matável. Assim, fica visível essa leitura dirigida ao totalitarismo como um regime político-ideológico que permanece operante numa cultura colonial (Mbembe, 2017).

Neste cenário, também emergem figuras autoritárias que prometem a restauração da "paz" a partir de uma constante guerra nos territórios, que mantém um estado de exceção permanente às populações que vivenciam estas realidades mediadas pela violência. Ocorre um processo de abandono das políticas estatais e o uso político do medo da violência, produzindo o desejo pela eliminação do inimigo e a adesão ao pensamento de líderes autoritários e fascistas (Mbembe, 2017).

Assim como pontua a filósofa Arendt (1998), o papel do líder nos regimes totalitários é certamente um lugar de poder, controle e de direito sobre outras vidas. Para tanto, o líder precisa enaltecer um mundo fictício e torná-lo capturado pelos sujeitos, assim, transformando essa ficção social como realidade do cotidiano e nos modos de produção social. Assim, é preciso que o líder também garanta que as leis estabelecidas pelo próprio regime sejam preservadas e estabilizadas, pois o líder como figura de regime ideológico e político personifica a garantia de que surjam novos modos de vida na sociedade totalitária.

Por isso, Arendt retorna para $\mathrm{Kant}^{3}$, o famoso imperativo categórico de Kant - "Aja de tal modo que a máxima de sua ação possa tornar-se uma lei universal" (Arendt, 1994) para aproximar a relação entre razão e vontade a fim de explicitar o quanto essas dimensões da condição de ser homem se entrelaçam em suas ações com o mundo e com o outro. Nitidamente, é esse agir que provoca o direito de governar, de deter um poder, de estabelecer um regime e uma conduta de vida social. Há sobretudo a possibilidade de instaurar a persuasão aos seres humanos, e por

\footnotetext{
${ }^{3}$ Como aponta Kant (2012, p. 19) "um ser humano pode adiar sua própria iluminação e mesmo assim apenas por um curto período de tempo, com relação aquilo que é sua responsabilidade saber. Mas renunciá-la para sua própria pessoa e mais ainda para seus descendentes significa violar e pisotear os direitos sagrados da humanidade". Este ponto Kant considera o "iluminismo" como a razão, ponto de reflexão pelo qual, o filósofo discute o juízo como condição não dado somente pelo empirismo, mas aplicado a crítica judicativa dos fenômenos.
} 
isso, a crítica é dada ao questionamento do que o indivíduo faz dele para si e julga ainda que se mostra paradoxalmente, para o outro somente dois caminhos possíveis, uma vida coercitiva subordinada ao poder ou uma vida exterminada (Correia, 2013).

Mbembe (2017) afirma que, anterior ao movimento do regime totalitário, a humanidade já teria se constituído em base sob esse efeito através do regime escravocrata, sobretudo com a colonização. Esta seria capaz de subsidiar as atrocidades que vieram posteriormente como guerras e campos de extermínio. Isso acontece, porque, para o autor, as colônias não são atravessadas por uma distinção entre o inimigo e não inimigo, ou seja, não há uma mobilização de tornar visível essa diferença que coloca as colônias entre uma díade alternada ou paralela entre guerra e paz caminhando na mesma direção.

Nesse sentido, cabe a discussão acerca da Necropolítica e como esta opera no campo da produção de subjetividades no Brasil, o que é interessante para se pensar as estratégias de enfrentamento do autoritarismo crescente que tem se vivido no país. Para o Mbembe (2017) a necropolítica é uma tecnologia política de produção e de gestão da morte. Não basta produzir a morte é necessário gerir os modos de morrer, sendo uma proposta para dar conta do fenômeno autoritarismo/racismo (que se associam na produção de violências), da destruição massiva de pessoas e da criação de mundos de morte (produzir certas populações como mortos-vivos, ou seja, como não pessoas, como não humanas, como não cidadãs) que é algo que atinge um número significativo da parcela da população que são as juventudes pobres e negras das periferias. O pressuposto inicial que o Mbembe traz sobre a necropolítica a expressão máxima do que o Foucault chama de poder de soberania como a capacidade de ditar quem pode viver e quem deve morrer (Mbembe, 2017).

Ainda sobre essa problemática, o medo se reverbera como anúncio ao terrorismo e artifício para a produção da imagem do inimigo, porque a ameaça não somente está presente nos campos de guerra bélica. Ela está presente no cotidiano. Com isso, a retificação corriqueira do medo nessas sociedades mostra como o individual e social estão entrelaçados (Martin-Baró, 2017). Partimos da afirmação do autor que "em última instância, só existe democracia liberal com os suplementos do servil e do racial, do colonial e do imperial. Este desdo- bramento inaugural é típico da democracia liberal" (Mbembe, 2017, p. 153). Pode-se identificar que a colonização só instituiu novas faces à luz do neoliberalismo e do capitalismo velhas formas de administrar os excluídos.

Neste cenário de formação política, a democracia-social na América Latina se ordenou historicamente nas "democracias conservadoras" com continuadas reformas tradicionais de exclusão travestida pela "Guerra psicológica", ou seja, uso da violência produzida (caráter ideológico atrelado ao medo psicológico) para conservação de privilégios das elites. A partir desse artifício de construção psicológica do medo social, há reificação do imaginário de proteção e exposição das desigualdades sociais que se perpetuam (Martin-Baró, 2017). É nesse campo de problematização que Bicalho, Kastrup e Reishoffer (2012) afirmam o quão é importante renunciar a compreensão de "classes perigosas" como está posta e enraizada no combate e agenciamento ao medo do crime. Uma vez que essa concepção reforça a discriminação de exclusão social e autoriza a violência estatal nas suas diversas facetas.

Desse modo, se o campo da segurança pública conduz a premissa de comportamentos desviantes contra a ordem social, isto se reflete na lógica causal que ainda continua se trabalhando o conceito de criminalidade. Assim, esses desvios comportamentais de condutas são combatentes em uma sociedade democrática, porque é típico no neoliberalismo que a norma seja acima de tudo fortaleza da democracia. Com isso, impossibilita-se o rompimento da estigmatização das classes perigosas e de uma violência perversa contra esses indivíduos (Bicalho et al., 2012).

Ainda sob essa perspectiva pós-colonial, a Spivak (2010) na obra intitulada Pode o subalterno falar? complementa com a discussão sobre a formação da elite sob a constituição do sujeito subalterno. A colonialidade inflou o desejo imperialista de desenvolvimento dos territórios colonizados sob a exclusão de minorias. Dessa forma, o capitalismo como produto desse avanço expandiu o imperialismo das elites com a formação periférica de indivíduos no recorte de raça e classe, reforçando a partir de marcadores o "verdadeiro subalterno". Se a formação da elite prevalece no constante movimento de vestimenta do desejo imperialista de subordinação, isto se torna possível porque o sujeito colonizador/imperialista autoritário produziu uma mesclagem entre uma 
deslegitimação violenta do saber epistêmico com o avanço do saber eurocêntrico e do desenvolvimento civilizatório. Com isso, o produto foi a (in)visibilidade do sujeito subalterno (Spivak, 2010).

Assim, corroborando com essa produção de subalterno, é no medo produzido pela insegurança de falta de segurança pública que o individualismo cresce. Dessa maneira, a classe que não pode comprar segurança privada fica a mercê da competitividade, da própria criminalidade e dos territórios de guerra. Dentro dessa lógica, o espaço público passa a vigorar sob o domínio da insegurança, pois a vida em comunidade é desmontada de direitos. O medo então ganha como destaque um lugar fundamental nessa artimanha, uma relação vertical e de disputa entre os próprios sujeitos, grupos e classes excluídas pelo sistema (Reishoffer, e Bicalho, 2009).

Nesse sentido, o debate interseccional posiciona-se como uma forma de dar ênfase nas problemáticas das populações estigmatizadas e oprimidas pela base colonial dos países eurocêntricos. Assim, são os marcadores da desigualdade que podem apontar novos caminhos de reflexões para a atualidade. Pode-se, assim, desconstruir uma série de estereotipias sobre os mitos de que a discriminação velada pelos discursos que não possibilitam agenciar esses marcadores na análise dos fenômenos sociais (Crenshaw, 2002).

\section{Conclusão}

É necessário pensar nos modos pelos quais é possível resistir aos processos de dominação e captação da singularidade pelo capitalismo. Reflete-se que violência se aplica ao engendramento da criminalidade e das formas de violência urbana a partir da individualização e do aniquilamento de sujeitos.

Consonante com isso, quando se analisa o campo da segurança pública, pretende-se desdobrar através da análise interseccional com os marcadores de raça e classe. Discute-se uma articulação da realidade política e social na produção de subjetividades. Isto se mostra relevante ao passo que contribui com apontamentos históricos da construção dos fenômenos de medo do crime e autoritarismo, como visto nos resultados discutidos em torno do locus da pesquisa. Assim, ratificamos que esse debate proposto possa se desdobrar como potente abertura de investigação em que o debate interseccional e pós-colonial tem mostrado grande importância para problematizar a estrutura social, as relações sociais e as subjetividades produzidas no cotidiano.

Isso aponta para a necessidade de novos olhares para uma produção de conhecimento das desigualdades sociais e processos de exclusão, e na tangente desse campo, o espaço da segurança pública como produtor de fenômenos sociais e subjetivações não marginalizadas ou aniquiladas pela violência urbana.

\section{Referências}

Accorssi, A., Scarparo, H., \& Guareschi, P. (2012). A naturalização da pobreza: reflexões sobre a formação do pensamento social. Psicologia \& Sociedade, 24(3), 536-546. https://doi.org/10.1590/S0102-71822012000300007

Adorno, T.W., Brunswik-Frenkel, E., Levinson, D. J., \& Sanford, R. N. (1950). The authoritarian personality. Berkeley: The Norton Library.

Adorno, T. W., \& Horkheimer, M. (2006). Dialética do esclarecimento: Fragmentos filosóficos. Rio de Janeiro, RJ: Jorge Zahard.

Arendt, H. (1994). On the nature of totalitarianism. In: H. Arendt (Org.), Essays in understanding: 1930-1954 (pp. 328-360). New York: Harcourt Brace.

Arendt, H. (1998). Origens do totalitarismo. São Paulo, SP: Companhia das Letras.

Associação Brasileira de Empresas de Pesquisa - ABEP. (2017). Critério Brasil 2017. São Paulo, SP: o autor. Recuperado de http://www.abep.org/criterio-brasil

Bento, M. A. (2009). Branqueamento e branquitude no Brasil. In: I. Carone, \& M. A. Bento. (Orgs.), Psicologia do racismo no Brasil: estudos sobrebranqueamento e branquitude no Brasil. Petropolis, RJ: Vozes.

Bernardino-Costa, J. (2015). Decolonialidade einterseccionalidade emancipadora:A organização política das trabalhadoras domésticas no Brasil. Sociedade e Estado, 30(1), 147-163. https://doi.org/10.1590/S0102-69922015000100009

Bicalho, P. P. G., Kastrup, V., \& Reishoffer, J. C. (2012). Psicologia e segurança pública: Invenção de outras máquinas de guerra. Psicologia \& Sociedade, 24(1), 56-65. https://doi.org/10.1590/S0102-71822012000100007 
Brasil. Ministério da Justiça. Departamento Penitenciário Nacional. (2017). Levantamento Nacional de Informações Penitenciária: atualização junho de 2016. Recuperado de http://depen.gov.br/DEPEN/noticias-1/noticias/ infopen-levantamento-nacional-de-informacoes-penitenciarias-2016/relatorio_2016_22111.pdf

Cerqueira, D. R. C., Lima, R. S., Bueno, S., Neme, C., Ferreira, H., Coelho, D. et al. (2018). Atlas da violência 2018. Rio de Janeiro, RJ: IPEA.

Correia, A. (2013). Arendt e Kant: Banalidade do mal e mal radical. Argumentos, 5(9) 63-78.

Crenshaw, K. (2002). Documento para o encontro de especialistas em aspectos da discriminação racial relativos ao gênero. Revista Estudos Feministas, 10(1), 171-188. https://doi.org/10.1590/S0104-026X2002000100011

Crochik, J. L. (2017). Personalidade autoritária e pesquisa empírica com a Escala F: alguns estudos brasileiros. Impulso, 27(69), 49-64. https:// doi.org/10.15600/2236-9767/impulso.v27n69p49-64

Crochík, J. L., Casco, R., Ceron, M., Catanzaro, F. O. (2009). Relações entre preconceito, ideologia e atitudes frente à educação inclusiva. Estudos de Psicologia (Campinas), 26(2), 123-132. https://doi.org/10.1590/S0103166X2009000200001

Fanon, F. (2008). Pele negra, máscaras brancas. Salvador, BA: Editora Edufba.

Fórum Brasileiro de Segurança Pública (2017). Medo da violência e o apoio ao autoritarismo no Brasil: índice de propensão ao apoio a posições autoritárias. São Paulo, SP: o autor.

Grosfoguel, R. (2016). A estrutura do conhecimento nas universidades ocidentalizadas: racismo/sexismo epistêmico e os quatro genocídios/epistemicídios do longo século XVI. Sociedade e Estado, 31(1), 25-49. https://doi. org/10.1590/S0102-69922016000100003

IBGE - Instituto Brasileiro de Geografia e Estatística. (2017). Pesquisa nacional por amostra de domicílios contínua: Educação 2016. Recuperado de https://www.ibge.gov.br/estatisticas-novoportal/sociais/trabalho/17270-pnad-continua.html?edicao=17274

IBGE - Instituto Brasileiro de Geografia e Estatística. (2018). Pesquisa nacional por amostra de domicílios contínua: Rendimentos de todas as fontes 2017. Recuperado de https://www.ibge.gov.br/estatisticas-novoportal/sociais/ populacao $/ 17270$-pnad-continua.html?edicao=20635

Kant, I. (2012). Filosofia da História: Textos extraídos das obras completas de Kant (Coleção Fundamentos da Filosofia). São Paulo, SP: Cone.

Lima, M. E. O, \& Vala, J. (2004). As novas expressões do preconceito e do racismo. Estudos de Psicologia, 9(3), 401411.

Maranhão, J. H., Colaço, V. D. F. R., Santos, W. S. D., Lopes, G. S., \& Coêlho, J. P. L. (2014). Violência, risco e proteção em estudantes de escola pública. Fractal: Revista de Psicologia, 26(2), 429-444. http://dx.doi.org/10.1590/1984$0292 / 853$

Martín-Baró, I. (2017). Da guerra suja à guerra psicológica: o caso de El Salvador. In: I. Martín-Baró, Crítica e libertação na Psicologia: Estudos psicossociais (pp. 271-285). Petrópolis, RJ: Vozes.

Mbembe, A. (2017). Políticas da inimizade (M. Lança, trad.). Lisboa: Antígona Editores Refractários.

Moura Junior, J. F., \& Ximenes, V. M. (2016). A identidade social estigmatizada de pobre: uma constituição opressora. Fractal: Revista de Psicologia, 28(1), 76-83. https:// doi.org/10.1590/1984-0292/1051

Noronha, C.V., \& Paes-Machado, E. (2013). Segurança pública: polícia, democracia e autoritarismo. Espacio Abierto, 22(3), 649-666.

Reishoffer, J. C., \& Bicalho, P. P. G. (2009). Insegurança e produção de subjetividade no Brasil contemporâneo. Fractal: Revista de Psicologia, 21(2), 425-444. https://doi.org/10.1590/S1984-02922009000200015

Rocha, E. F. (2015). O negro no mundo dos ricos: um estudo sobre a disparidade racial de riqueza no Brasil com os dados do censo demográfico de 2010 (tese de doutorado). Universidade de Brasília, Brasília, DF, Brasil.

Schwartzman, S. (2007). Bases do autoritarismo brasileiro (4a ed.). Rio de Janeiro: Publit.

Smolen, J. R., Araújo, E. M. (2017). Raça/cor da pele e transtornos mentais no Brasil: uma revisão sistemática. Ciência \& Saúde Coletiva, 22(12), 4021-4030. https://doi.org/10.1590/1413-812320172212.19782016

Souza, J. (2017). A elite do atraso: Da escravidão à Lava Jato. Rio de Janeiro, RJ: Leya. 
Spivak, G. C (2010). Pode o subalterno falar? Belo Horizonte, MG: Editora UFMG.

Paes-Machado, E., Noronha, C. V. (2002). Padrões de trabalho e tendência do uso da força policial no Brasil. In: R. R. P. Lyra (Org.). Direitos humanos: Os desafios do século XXI: Uma abordagem interdisciplinar (pp. 225-240). Brasília, DF: Brasília Jurídica.

Wacquant, L. J. D. (2001). Punir os pobres: A nova gestão da miséria nos Estados Unidos. Rio de Janeiro, RJ: Freitas Bastos.

Waiselfisz, J. J. (2016). Mapa da violência: Homicídios por armas de fogo no Brasil. Brasília, DF: Flacso.

Williams, D. R., \& Priest, N. (2015). Racismo e saúde: Um corpus crescente de evidência internacional. Sociologias, 17(40), 124-174. https://doi.org/10.1590/15174522-017004004

Zamora, M. H. R. N. (2012). Desigualdade racial, racismo e seus efeitos. Fractal Revista de Psicologia, 24(3), 563-578. https://doi.org/10.1590/S1984-02922012000300009

Tadeu Lucas de Lavor Filho

Graduado em Psicologia pelo Centro Universitário Dr. Leão Sampaio (Unileão). Mestrando do Programa de Pósgraduação em Psicologia da Universidade Federal do Ceará (UFC), Fortaleza - CE. Brasil.

E-mail: lucasamoha@gmail.com

(iD) https://orcid.org/0000-0003-2687-1894

Vilkiane Natercia Malherme Barbosa

Mestranda em Psicologia pela Universidade Federal do Ceará (UFC), Fortaleza - CE. Brasil.

E-mail: vilkimalherme@outlook.com

(iD https://orcid.org/0000-0002-3048-9316

Damião Soares de Almeida Segundo

Mestrando em Psicologia pela Universidade Federal do Ceará (UFC), Fortaleza - CE. Brasil.

E-mail:damiao_soares@hotmail.com

(iD https://orcid.org/0000-0003-2407-0583

James Ferreira Moura Júnior

Doutor em Psicologia pela Universidade Federal do Rio Grande do Sul (UFRGS), Porto Alegre - RS. Docente da UNILAB e da Pós-graduação em Psicologia da Universidade Federal do Ceará (UFC), Fortaleza - CE. Brasil.

E-mail: james.mourajr@unilab.edu.br

(iD) https://orcid.org/0000-0003-0595-5861

Paulo de Martino Jannuzzi

Doutor em Demografia pela Universidade Estadual de Campinas (Unicamp), Campinas - SP. Brasil. Docente da Escola Nacional de Ciências Estatística do IBGE (ENCE), Rio de Janeiro - RJ. Brasil.

E-mail: paulo.jannuzzi.br@gmail.com

(iD) https://orcid.org/0000-0003-3528-7497

\section{Renato Sérgio de Lima}

Doutor em Sociologia pela Universidade de São Paulo. (USP), São Paulo - SP. Brasil. Docente da Fundação Getulio Vargas (FGV), São Paulo - SP. Brasil. Diretor-Presidente do Fórum Brasileiro de Segurança Pública.

E-mail: renato.lima@forumseguranca.org.br

(iD https://orcid.org/0000-0002-0935-699X 
Endereço para envio de correspondência:

Programa de Pós-graduação em Psicologia da UFC, Av. da Universidade, 2762, Benfica - CEP: 60.020-180 -

Fortaleza/CE - Área 2 do Centro de Humanidades - Bloco Didático Prof. Ícaro de Sousa Moreira.

Telefone: (85) 3366-7661 / 3366-7651. E-mail: lucasamoha@gmail.com

Recebido 19/08/2018

Aprovado 23/08/2018

Received 08/19/2018

Approved 08/23/2018

Recibido 19/08/2018

Aceptado 23/08/2018

Como citar: Lavor Filho, T. L., Barbosa, V. N. M., Almeida Segundo, D. S., Moura Jr., J. F., Jannuzzi, P. M., \& Lima, R. S. (2018). Análises interseccionais a partir da raça e da classe: Medo do crime e autoritarismo no Brasil. Psicologia: Ciência e Profissão, 38(n.spe.2), 223-237. https://doi.org/10.1590/1982-3703000212376

How to cite: Lavor Filho, T. L., Barbosa, V. N. M., Almeida Segundo, D. S., Moura Jr., J. F., Jannuzzi, P. M., \& Lima, R. S. (2018). Intersectional analyses from race and class: Fear of crime and authoritarianism in Brazil. Psicologia: Ciência e Profissão, 38(n.spe.2), 223-237. https://doi.org/10.1590/1982-3703000212376

Cómo citar: Lavor Filho, T. L., Barbosa, V. N. M., Almeida Segundo, D. S., Moura Jr., J. F., Jannuzzi, P. M., \& Lima, R. S. (2018). Análisis interseccionales a partir de la raza y de la clase: Miedo del crimen y autoritarismo en Brasil. Psicologia: Ciência e Profissão, 38(n.spe.2), 223-237. https://doi.org/10.1590/1982-3703000212376 